\title{
Flow. An exploration of the mindsets and behaviours of designers in their creative ecosystem
}

\section{Raul Sarrot}

Auckland University of Technology

How might Designers transcend the barriers to creativity to achieve an ideal state of flow during their Design process? What type of ecosystems and other environmental agents affect their creative mindsets and behaviours during their process? How resilience and mental wellbeing play a role in their work during challenging times? How different cultural environmental backgrounds could play a role in troubleshooting roadblocks for creativity? What are the personal, societal and cultural impacts of recent Covid lockdowns in the Design process and do digital environments affect the ability to sustain a healthy design practice? How having the recent mindset of designing for a globalised world reacts to the reality of being in -and designing from- Aoteroa New Zealand's safe 'bubble'? How this new fluid reality could affect the mindset and behaviours of current and future Designers?

Tracing parallels between Design education and industry-based practice, Flow is a research project that explores the mindsets and behavious of Designers during their creative process. Particularly, it delves into the Designers' ecosystems taking into consideration the impact and influence of the different components and the conditions of digital and physical environments both chosen or imposed both in academic world and in industry. Flow goes beyond researching mindsets and behaviours. It also explores what could constitute potential bridges and barriers to creativity and what could ignite or enable positive and productive creative attitudes in Designers.

Based on foundational art essays, such as Wassily Kandinsky's classic 'Concerning the Spiritual in Art' and Hundertwasser's 'Five Skins'; and blending in points of view of traditional graphic or brand designers
Orcid number 0000-0003-1819-626X (such as Milton Glaser and Michael Bierut) and combining this with Positive Psychology concepts (such as Csikszentmihalyi's optimal experience) and primary research done specifically by the author, this presentation challenges paradigms and contrasts core design principles and philosophies. It balances the tensions between the individual spark of creativity, the playful serendipity and the 'inventor's ligthbulb mindset' and contrasts it with different creative processes, from the specialist's apprentice/master craftsmanship model to more contemporary methodologies or techniques such as Design Thinking or Agile and their co-creation, prototyping and iteration modules. This provides the backdrop where mindsets and behaviours and the creative ecosystems are explored.

As a piece of research, Flow doesn't offer final crystalised answers or solutions yet instead poses critical questions and offers an open dialogue with diverse points of view based not only on specific primary and secondary research conducted over the last 5 years by the author yet also feeds from the author's insights, a designer and academic with 30 years experience of combined practice in academia and industry field-work at a global scale.

KEYWORDS

Flow, Creative Process, MIndsets, Behaviours, Design 